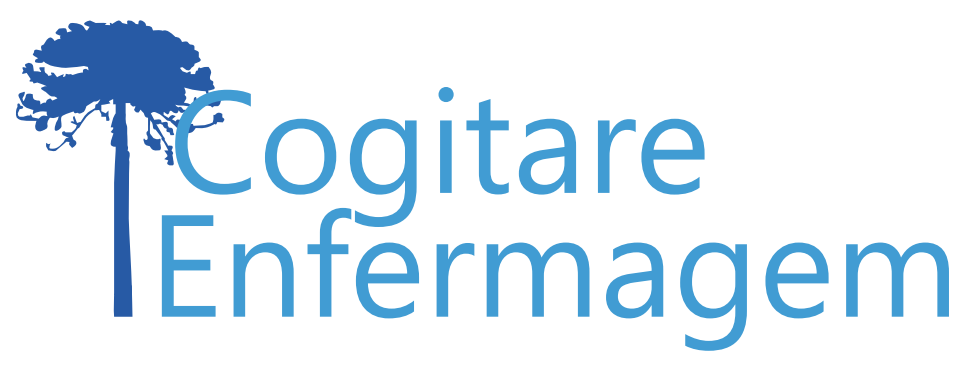

\title{
TRAVESTIS PROFISSIONAIS DO SEXO E QUALIDADE DE VIDA: VISIBILIZANDO OUTRAS CONCEPÇÕES
}

\section{TRANSVESTITES WHO ARE SEX WORKERS AND QUALITY OF LIFE: VIEWING OTHER CONCEPTIONS}

\author{
Ana Lilia Souza Barbosa ${ }^{1}$ (i) \\ Alef Diogo da Silva Santana² \\ Ednaldo Cavalcante de Araújo ${ }^{1}$ \\ Jefferson Wildes da Silva Moura ${ }^{1}$ (1) \\ Marcos Soares de Lima ${ }^{3}$ (1)
}

\begin{abstract}
Objective: to understand the perception of quality of life of transvestites who are sex workers. Method: a qualitative and exploratory study. The starting point was a social space in the city of Recife, Pernambuco, Brazil. The participants were located through the snowball technique. A semistructured questionnaire with guiding questions was applied, with participation of seven individuals, by means of theoretical saturation. The data were recorded and analyzed based on content thematic analysis and similarity analysis. For validation and reliability, methodological and researcher triangulation was adopted. Results: three classes were obtained: "Respect for the social name and recognition of the trans identity"; "The importance of formal insertion and employability" and "Social well-being, education and housing". The result was a similarity tree with the most significant words. Conclusion: It was possible to identify other narratives about the quality of life of transvestites who are sex workers, which breaks with the common sense that relates any and all marginalized and unintelligible conception to transvestites.
\end{abstract}

DESCRIPTORS: Quality of Life; Transgender People; Sex Workers; Sexual and Gender Minorities; Nursing.

COMO REFERENCIAR ESTE ARTIGO:

Barbosa ALS, Santana AD da S, Araújo EC de, Moura JWS da, Lima MS de. Travestis profissionais do sexo e qualidade de vida: visibilizando outras concepções. Cogit. Enferm. [Internet]. 2021 [acesso em "colocar data de acesso, dia, mês abreviado e ano"]; 26. Disponível em: http://dx.doi.org/10.5380/ce.v26i0.76961. 
O "ser homem" ou "ser mulher" na sociedade ocidental está pautado na lógica binária, atribuído socialmente antes mesmo do nascimento, resultando na imposição quanto à adequação do indivíduo ao gênero ${ }^{(1-2)}$. Os estudos que permeiam o campo da sexualidade e gênero têm contribuído na discussão ao questionar os padrões estabelecidos pela cisnormatividade. Logo, reconhece-se que a identidade de gênero vai além dos aspectos biológicos, pois é a forma de autorreconhecimento do indivíduo com o gênero com o qual se identifica. Neste contexto, situam-se as pessoas transgênero - homens e mulheres transexuais, travestis e pessoas não-binárias ${ }^{(1)}$.

A não adequação à cis-heteronormatividade corrobora para que as travestis vivenciem a transfobia, tendo negado o acesso ao exercício de sua cidadania e de direitos básicos como educação e saúde; dificuldades no mercado de trabalho formal; redes de apoio fragilizadas; estigma, discriminação, e até a morte. Esse cenário pode potencializar contextos vulnerabilizadores, que vão contribuir para sua inserção no mercado sexual, tido como uma das únicas fontes de sobrevivência ${ }^{(2-3)}$.

A qualidade de vida é multidimensional e engloba o bem-estar físico, funcional, social e psicológico, ou seja, não se restringe apenas à saúde, dialogando com outros campos de conhecimento $^{(4)}$. A vivência das travestis nas problemáticas sociais impacta e influencia a sua qualidade de vida, que possui, inclusive, expectativa de vida de 35 anos ${ }^{(5)}$.

Nota-se que os estudos destinados à qualidade de vida, em especial das travestis, são incipientes e centrados em questões biomedicalizantes, sobretudo, na influência do HIV/AIDS em suas vidas. Assim, é preciso considerar a percepção do indivíduo sobre a sua qualidade de vida por meio de abordagens que ultrapassem aspectos biomédicos, considerando a constituição dos processos sociais. Posto este panorama, este estudo visou compreender a percepção de qualidade de vida de travestis profissionais do sexo.

\section{MÉTODO}

Trata-se de um estudo qualitativo, descritivo e exploratório. O estudo foi realizado no primeiro semestre de 2020, na região metropolitana de Recife, Pernambuco, Brasil, tendo como ponto de partida (e não como um setting) um espaço social direcionado para o atendimento social das especificidades das pessoas LGBT+. Ressalta-se que parte da produção dos dados foi norteada pelas normas de prevenção instituídas pelas autoridades sanitárias devido à pandemia de covid-19.

A seleção das participantes foi mediante a técnica em cadeia snowbal/(6). A população do estudo se deu por conveniência, não probabilística, seguindo o critério de saturação teórica. Participaram, assim, sete travestis, maiores de 18 anos, de qualquer orientação sexual e que fossem profissionais do sexo.

Como instrumento de coleta de dados, foi utilizado um questionário com questões sociodemográficas: idade, estado civil, escolaridade, raça, renda, com quem reside e se procura os serviços de saúde com frequência. Realizaram-se entrevistas guiadas por um roteiro semiestruturado, composto por duas perguntas norteadoras: 1) Fale-me o que você entende por qualidade de vida; 2) Na sua opinião, você tem qualidade de vida? Se sim, explique.

Para manter a fidedignidade e validade na coleta de dados ${ }^{(7)}$, foram aplicados dois testes piloto para evitar interpretações errôneas, os quais não foram incluídos na amostra final. Todas as entrevistas foram gravadas mediante assinatura do termo de cessão e autorização 
presente no Termo de Consentimento Livre e Esclarecido. A gravação foi realizada por meio de dois aparelhos de áudio, com duração média de 35 minutos. As entrevistas foram transcritas na íntegra e, após a análise, foram apresentadas às interlocutoras, que puderam realizar comentários e/ou correções objetivando validar o que foi transcrito.

A produção dos dados empíricos iniciou com a aproximação dos pesquisadores com uma informante chave do espaço social inicial. A partir do acesso à primeira participante, houve a apresentação da pesquisa, seus objetivos e intencionalidades, que após o estabelecimento do convite formal, aceitou participar. A aplicação do questionário e realização das entrevistas aconteceram em salas reservadas. Ao fim da entrevista, solicitavase à participante a indicação de uma nova informante. Houve duas recusas na produção dos dados devido às interlocutoras alegarem não participarem de estudos conduzidos por pessoas cisgênero.

A saturação dos dados ocorreu a partir da sexta entrevista, oportunizando a realização de mais uma entrevista para confirmação(8). Para determinar o ponto exato da saturação, recorreu-se a oitos passos: a) registro dos dados brutos; b) imersão nos achados; c) seleção dos achados individuais de cada discurso; d) agrupamentos dos achados em temáticas ou pré-temáticas; e) nomeação; f) visualização das pré-temáticas em uma tabela; g) observação da saturação em cada pré-tema; h) visualização da saturação ${ }^{(8)}$.

A análise dos dados empíricos empregou duas etapas: a primeira, análise de conteúdo temática ${ }^{(9)}$, operacionalizada a partir da pré-análise, exploração do material e interpretação. Posteriormente, realizou-se análise do corpus mediante a técnica lexical, com suporte do programa Interface de R pourles Analyses Multidimensionnelles de Texteset et de Questionnaires (IRAMUTEQ) versão 0.7 alpha $2^{(10)}$, em que se aplicou o método da análise de similitude, que se baseia na teoria dos grafos e possibilita a relação entre palavras, originando a árvore de similitude. Para validação e confiabilidade, utilizaram-se a triangulação metodológica e de pesquisadores ${ }^{(11)}$.

Esta pesquisa atendeu às normas estabelecidas pela Resolução $n^{\circ} 466$, de 12 de dezembro de 2012 do Conselho Nacional de Saúde do Ministério da Saúde ${ }^{(12)}$. A coleta de dados foi iniciada após a aprovação do Comitê de Ética em Pesquisa Envolvendo Seres Humanos da Universidade Federal de Pernambuco, com parecer 3.967.127. Para a garantia do anonimato, os depoimentos foram identificados por "Participante", seguida pelo número arábico correspondente à ordem da coleta de dados.

\section{RESULTADOS}

Participaram sete travestis profissionais do sexo, com idade média de 29,1 anos. Quatro participantes estão solteiras e três em relacionamento monogâmico afetivo estável; em relação

à escolaridade, quatro estudaram até o ensino primário, duas concluíram o ensino médio e apenas uma o ensino superior; três residem com a família, duas sozinhas e duas com seus companheiros. Quando indagadas sobre a frequência em relação à procura aos serviços de saúde, cinco referiram ir frequentemente, e duas ocasionalmente. Nenhuma possui filhos e as sete são de orientação sexual heterossexual.

Todas as participantes do estudo são provenientes de cidades que abrangem a região metropolitana do Recife-PE. Nenhuma participantes exerce trabalho formal, excluindo-se a profissão do sexo. Em relação à situação econômica, seis consideram ruim, vivendo em um contexto socioeconômico desfavorável, e uma participante considera média.

O corpus textual analisado, conforme a Figura 1, evidencia os resultados da árvore de similitude com a identificação das palavras que possuem mais significância e conexidade 
entre os termos apresentados, demonstrando a percepção de qualidade de vida das interlocutoras.

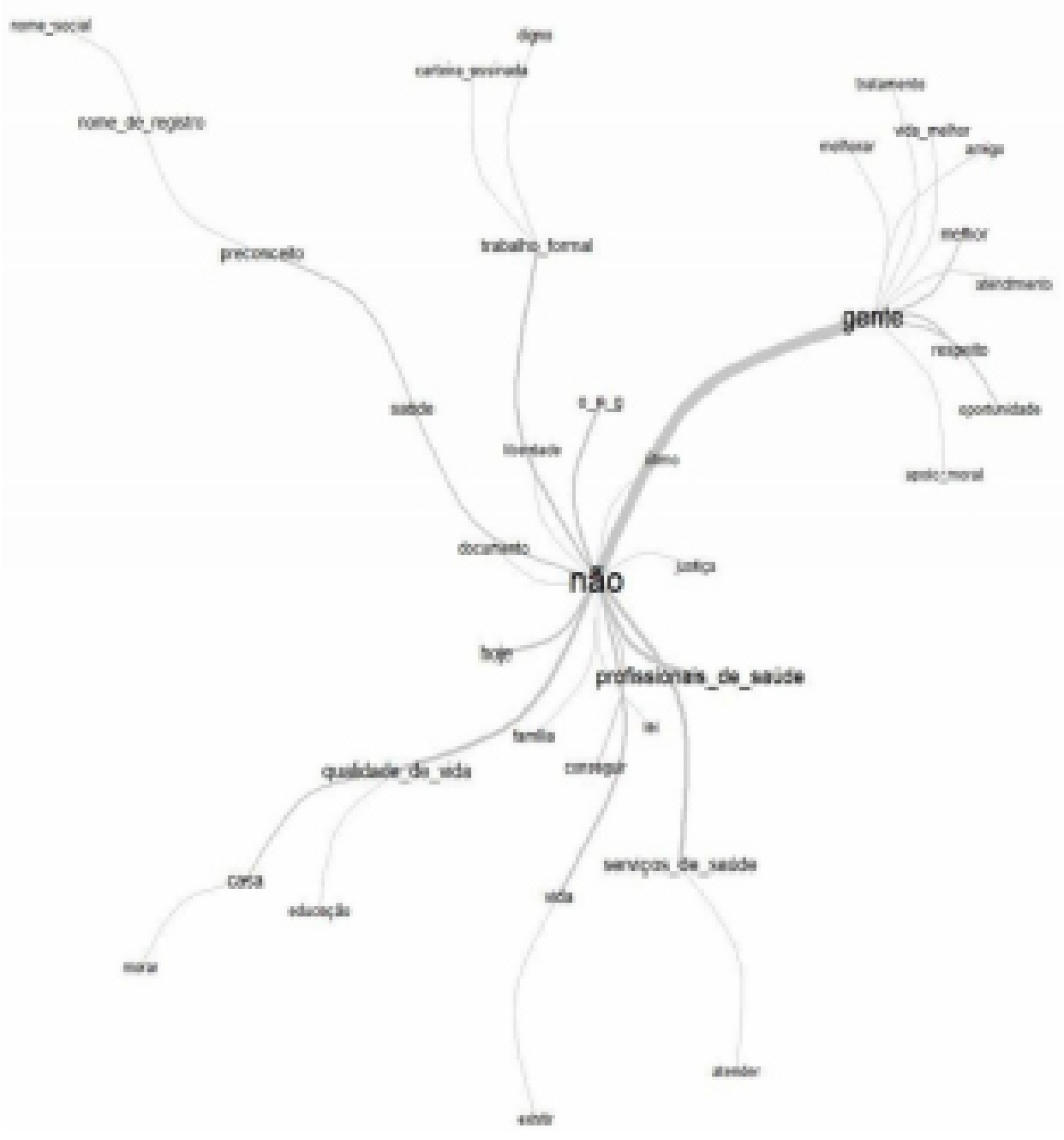

Figura 1 - Árvore ilustrativa da análise de similitude da qualidade de vida das travestis profissionais do sexo. Recife, PE, Brasil, 2020

Fonte: Autores (2020)

Mediante a análise de conteúdo temática, obtiveram-se três classes: "Respeito ao nome social e reconhecimento da identidade trans"; "A importância da inserção e empregabilidade formal"; e "Bem-estar social, educação e moradia".

A classe "Respeito ao nome social e reconhecimento da identidade trans" foi caracterizada por representar a importância do respeito ao nome social, pois este é configurado como parte fundamental da identidade das interlocutoras, correspondendo ao direito de exercício da sua cidadania e legitimação da sua identidade:

Pra gente que sofre muito seria ótimo o respeito, primeiramente, ao chamar pelo nome que desejamos ser chamadas, além de dignidade pra gente. Mas do ponto de vista deles, a gente nunca vai ser digna. (Participante 1)

Por causa de documento, a maioria antes não ia procurar os outros serviços de saúde, o constrangimento de ser chamada pelo nome de registro, outros motivos como preconceito, 
acaba afetando a saúde de todas as meninas porque ninguém quer sair de casa pra se sentir mal. (Participante 2)

Tive que passar pelo preconceito com o nome de registro, isso me incomodava muito, principalmente quando eu estava começando a minha transição. Eu sempre estava em serviços de saúde esperando a minha vez e eles sempre chamavam pelo nome masculino, eu levantava com o maior constrangimento e todo mundo ficava me olhando com o maior preconceito. (Participante 3)

Já passei por algumas situações relacionadas ao nome de registro e nome social. Você chega no lugar muitos nem reconhecem que você é uma travesti, grita seu antigo nome na frente de todo mundo e quando levanto passo pelo maior constrangimento e preconceito, porque todo mundo está esperando por um homem se levantar, quando vê levanta uma mulher. (Participante 4)

A classe "A importância da inserção e empregabilidade formal" evidencia a relevância do trabalho formal na qualidade de vida das entrevistadas em um contexto histórico, social e econômico de preconceito e exclusão.

Precisamos de oportunidade para ter um trabalho formal, pois por sermos travestis não somos obrigadas a estar na prostituição, a gente não é objeto sexual de ninguém, mas pela sociedade [eles querem] que a gente fique a vida toda na prostituição, mas a gente não quer, estamos ali porque somos obrigadas. (Participante 2)

Infelizmente as pessoas julgam o ser humano pela sua orientação sexual e identidade de gênero e não pelo profissional que você é, eles não dão a oportunidade de você mostrar a sua competência (Participante 1)

Com ensino superior, só julgam pela capa! Trabalho mesmo de carteira assinada eu só consegui quando não tinha me assumido, depois que me assumi travesti ninguém me dá nenhuma oportunidade de emprego. (Participante 5)

A situação está ruim pra todo mundo, mas pra nós com certeza é pior. Eu acho que é o preconceito, é muito difícil pra uma travesti arrumar um trabalho formal. Infelizmente eu concluí meus estudos, mas não consegui nenhum emprego, eu jurava que terminando o ensino médio já conseguiria, mas não, eu pensei totalmente diferente, porque até agora eu não arrumei nenhum trabalho de carteira assinada. (Participante 4)

Nunca consegui trabalhar em nenhum emprego com carteira assinada, já trabalhei em casa de família, mas nunca de carteira assinada. (Participante 2)

Então pra [eu] ter qualidade de vida é poder ter um trabalho formal de carteira assinada, sem o povo olhar feio pra pessoa, sem discriminação, sem ódio, sem preconceito, porque tem gente que olha pra você com ódio. (Participante 7)

A última classe demonstrou como a determinação social da saúde (DSS) se relaciona com os processos sociais e proporciona a promoção da qualidade de vida. Esta categoria foi denominada de "Bem-estar social, educação e moradia".

Qualidade de vida pra mim é ter acesso a uma boa alimentação, boa educação, boa renda, uma casa boa pra morar, ter uma vida melhor, ter um lazer, porque nenhum ser humano vive sem lazer, o corpo em si precisa de lazer, tem momentos que você trabalha demais e percebe que o corpo necessita relaxar. (Participante 5)

Ter qualidade de vida é a gente ter um trabalho digno, a gente ter uma casa própria pra morar, uma vida melhor, ter renda, oportunidade de ter educação. Eu não sou muito presa a bens materiais, mas ter uma casa própria, um trabalho de carteira assinada, ter a liberdade de sair na rua pra comprar qualquer coisa sem sofrer preconceito, é essencial pra ter qualidade de vida. (Participante 6) 
Qualidade de vida eu acho que é ter uma boa casa, se sentir bem e ter dinheiro para pagar minhas contas durante o mês, é a melhor qualidade de vida. (Participante 2)

Se eu digo pra você que qualidade de vida é ter uma boa alimentação, uma boa educação, um lazer, se eu não trabalho, como é que vou ter tudo isso? Impossível! (Participante 3)

O nome social é definido como a designação pela qual a pessoa transgênero se identifica e é reconhecida na sua rede de sociabilidade ${ }^{(13)}$. $O$ nome se constitui como uma das principais categorias analíticas enlaçadas na subjetividade das interlocutoras, tornando-se um importante fator no reconhecimento da sua identidade e legitimação da sua cidadania.

Foi apenas em 2016 que o Decreto 8.727 da Presidência da República do Brasi(13) possibilitou o uso do nome social e o reconhecimento da identidade de gênero de travestis e pessoas transexuais em toda a esfera pública federal. O reconhecimento e a importância do nome enquanto categoria que possui raízes nas suas histórias e processos sociais foi um elemento por muitos anos invisibilizado e negligenciado pelo Estado, divergindo, inclusive, do que é posto pela Constituição Federal de $1988^{(14)}$.

O constrangimento, medo, vergonha e sentimentos negativos ocasionados pela transfobia e incitados pela sociedade e mais notoriamente pelos profissionais de saúde, deslegitimam instrumentos legais que possibilitam e asseguram às pessoas transexuais 0 uso e respeito do nome social em todo âmbito do Sistema Unico de Saúde (SUS). A própria Política LGBT+ de 2013, instituída pela Portaria do Ministério da Saúde (MS) n².836, possui como compromisso a garantia dos direitos humanos, justiça e equidade na assistência à saúde integral às pessoas LGBT+ ${ }^{(15)}$.

Apesar dos respaldos legais, ainda há profissionais de saúde que reproduzem práticas desumanizadas, produzindo sofrimentos que vão, dentro dos múltiplos processos de invisibilização que esse grupo social experimenta, potencializar situações discriminatórias e de afastamento dos serviços de saúde. O desrespeito ao nome social é um dos fatores que afasta as travestis das unidades de saúde. No entanto, quando o profissional respeita esse direito, além de aproximar essa população dos serviços de saúde, corrobora para a efetivação da integralidade do SUS ${ }^{(16)}$.

É notório que os efeitos do respeito e utilização do nome social repercutem de forma positiva na vida das interlocutoras ${ }^{(17)}$. Identificam-se os benefícios como a possibilidade de inserção no mercado de trabalho sem a divergência do nome verbalizado e da aparência; além da melhora da autoestima e bem-estar, corroborando com a importância da articulação e efetivação desse direito por parte das instituiçõos e dos profissionais de saúde, a fim de possibilitar a integralidade da assistência e garantir atenção resolutiva às demandas das travestis. Esses fatores possuem intrínseca relação com a concepção de qualidade de vida das participantes, visto que há o respeito à sua identidade, história e existência. Essa questão pode ser observada na árvore de similitude, no lado superior esquerdo - expondo a necessidade de reconhecimento do nome social (o registro e o próprio nome civil se colocam como obstáculos dessa qualidade de vida).

A "Importância da inserção e empregabilidade formal" se constitui como uma categoria que denuncia como os processos sociais postos pela sociedade cis-heterossexual, sobretudo na esfera trabalhista, são construídos em uma lógica de quais corpos e vidas possuem o direito de acessar determinados equipamentos sociais. A importância das participantes em ter acesso a oportunidades de trabalhos que não se situem no mercado sexual é um aspecto que impacta em diferentes dimensões das suas vidas, algo denominado 
como desfiliação social(18) - indivíduos que ocupam determinados locais sociais por estarem privados de construírem potencialidades exigidas de acordo com o "perfil do mercado". Devido a características historicamente estigmatizadas e excluídas, estas pessoas acabam recorrendo ao trabalho informal e/ou à prostituição como forma de sobrevivência.

É possível estabelecer relações que objetificam e tipificam os corpos das travestis profissionais do sexo, interpretadas a partir da designação de espaços que permitem a sua presença, como as ruas ao anoitecer. $O$ senso comum permite não só associar as travestis à prostituição, como também reverberar um discurso que as localiza como indivíduos que não possuem necessidades sociais, ou ainda, que não possuem a dignidade de exercer a sua cidadania, construir famílias e relacionamentos, aspectos que influenciam na qualidade de vida. $\mathrm{Na}$ árvore de similitude, essa concepção está situada no centro, sinalizando como uma das principais evocações das participantes na análise, pois é o trabalho profissional formal, dentre outras questões, que vai possibilitar o seu exercício e reconhecimento pela sociedade e Estado como cidadã.

Cerca de $90 \%$ das travestis e transexuais convivem diariamente com a falta de oportunidade de empregos formais e recorrem ao trabalho sexual como principal fonte de renda para a sobrevivência(19). Apenas $4 \%$ se encontram em empregos formais, situação resultante de um conjunto de fatores que vão determinar a probabilidade e a chance das pessoas trans de serem inseridas no mercado de trabalho(19). Apesar de ser reconhecido que a baixa escolaridade é um dos fatores que pode dificultar o acesso das interlocutoras ao mercado de trabalho formal, as dificuldades não se limitam exclusivamente a isso, visto que há discriminação por parte das empresas e locais de trabalho cotidianamente ${ }^{(20)}$.

As insuficientes oportunidades tem grande impacto em suas socializações e, quando analisadas ainda na perspectiva do trabalho sexual, carregam todo o preconceito associado à profissão ${ }^{(21)}$. A conclusão dos estudos por algumas participantes não foi garantia da sua inserção no mercado de trabalho. As dificuldades e impossibilidade em obter um trabalho que ultrapasse a própria realidade do trabalho sexual influencia na qualidade de vida das interlocutoras, resultando em sentimento de impotência; não dignidade de vida; privação de exercer habilidades e capacidades pessoais; e não proporcionar/assegurar uma renda mensal, o que ocasiona instabilidade financeira e a não realização de planos e metas de vida.

Na categoria "Bem-estar social, educação e moradia", observa-se como a partir da influência da DSS há a produção de condições propícias para o estabelecimento de uma boa qualidade de vida. O conceito de saúde adotado pela Organização Mundial de Saúde considera a saúde um estado de bem-estar físico, mental e social, e não apenas a ausência de doença ${ }^{(22)}$. Esse conceito nos convida a refletir sobre essa "perfeição inatingível"(23). É importante reconhecer no contexto das interlocutoras, os processos, contexto social e realidade local para compreender a saúde de forma multidimensional e dinâmica, além de como a DSS vai influenciar e oportunizar acessos e vivências sociais ${ }^{(24)}$.

A educação é um fator potente, capaz de promover a redução das desigualdades sociais pois, além de proporcionar acesso à informação, capacita o indivíduo a compreender os processos sociais que vivencia. Cabe ressaltar que não é possível analisar a exposição a tamanha violência e processos vulnerabilizadores sem desafiar os processos sociais que impedem o acesso à educação pelas travestis, exigindo a reflexão crítica sobre a problemática. A análise direcionada à influência isolada da educação torna o discurso superficial, visto que há outras dinâmicas que se articulam com os DSŞ, algo similar quanto ao termo "determinantes sociais de saúde" que reflete a necessidade de caracterizar um domínio específico, tratando tais questões como algo externo ao indivíduo, de forma fixa e estática ${ }^{(24)}$, o que diverge com a discussão da problemática analisada aqui.

O acesso das travestis à educação é não só uma garantia de direito social, mas também uma condição sine qua non para potencializar as possibilidades de inserção no mercado de trabalho, proporcionando a compreensão e reivindicação dos seus direitos e uma emancipação política e de existência ${ }^{(14,25)}$. Os vocábulos relacionados à necessidade 
da moradia, emprego e oportunidade de educação foram evidenciados na árvore de similitude e se mostram necessárias, pois validam os achados científicos disponíveis na literatura nacional e internacional.

A identificação da moradia refletiu sentimentos que transcendem o aspecto físico relacionado aos bens materiais, estendendo-se a uma vida digna e respeitável, essencial no estabelecimento de medidas de promoção à qualidade de vida. A Declaração Universal dos Direitos Humanos de $1948^{(26)}$ defende que o direito à moradia é indispensável para sobrevivência e desenvolvimento do ser humano em termos de segurança, autonomia e independência, é algo que engrandece e possibilita a experiência de vida das nossas interlocutoras.

A principal limitação do estudo foi o difícil acesso dos pesquisadores - notoriamente cisgênero - às redes de sociabilidade das travestis profissionais do sexo. Essa questão pode ter limitado a indicação a outras possíveis interlocutoras, bem como o aprofundamento da temática. Recomendamos a necessidade de mais estudos empíricos que versem sobre a qualidade de vida das pessoas transgênero à luz de referenciais teóricos-metodológicos para além da área da saúde, pois a compreensão dos processos que influenciam a qualidade de vida desse grupo social possui como principais motores as opressões incitadas por estruturas de poder, o que pouco é abordado, discutido e investigado na área da Enfermagem.

\section{CONSIDERAÇÕES FINAIS}

A percepção das travestis profissionais do sexo sobre a qualidade de vida está relacionada com a necessidade de bem estar social; do respeito e legitimação do uso do nome social; do acesso à moradia digna; emprego formal que propicie maior conforto e renda para suas necessidades básicas e essenciais; ter o direito de transitar pelos espaços sociais sem julgamentos e preconceitos; ter acesso ao lazer, alimentação e livre tomada de decisões, aspectos que vão favorecer e estimular a sua autonomia e o direito de exercer a sua cidadania. Nesse contexto, compreender a influência dos DSS requer admitir que a exclusão social que alguns grupos vivenciam é influenciada pelos processos sociais que vão hierarquizar vidas dentro da grande estrutura social e capitalista que vivenciamos.

Enquanto contribuição à área de saúde e, de forma específica, à enfermagem, menciona-se não só as reflexões e problematizações realizadas ao decorrer do texto, possível de instigar outros pesquisadores a questionarem sua própria práxis, mas também a visualização de realidades outras quando há discussão a respeito das vivências e experiências das travestis profissionais do sexo. Historicamente, tais corpos são não só lidos socialmente como ininteligíveis, mas também tidos enquanto meros objetos de estudos onde pesquisas que versam sobre as experiências de pessoas transgênero se concentram, em grande medida, em temáticas que mais reforçam do que contribuem para a redução do estigma e discriminação.

Assim, foi possível identificar narrativas sobre a qualidade de vida das travestis profissionais do sexo que fissuram o senso comum que atrela às travestis toda e qualquer concepção negativa e marginalizada. 
da construção de identidade de gênero fluído nos padrões normativos. Psicologia.pt [Internet]. 2019 [acesso em 02 set 2020]. Disponível em: https://www.psicologia.pt/artigos/textos/A1346.pdf.

2. Magno L, Silva LAV da, Veras MA, Pereira-Santos M, Dourado I. Stigma and discrimination related to gender identity and vulnerability to HIV/AIDS among transgender women: a systematic review. Cad. Saúde Pública [Internet]. 2019 [acesso em 02 set 2020]; 35(4). Disponível em: https://doi. org/10.1590/0102-311X00112718.

3. Abreu PD de, Araújo EC de, Vasconcelos EMR de, Moura JW da S, Heráclio I de L, Santos ZC dos, et al. Quality of life of transexual women living with HIV/Aids. Cogitare Enferm. [Internet]. 2019 [acesso em 03 set 2020]; 24. Disponível em: http://dx.doi.org/10.5380/ce.v24i0.59749.

4. Souza JGS, Pamponet MA, Souza TCS, Pereira AR, Souza AGS, Martins AME de BL. Tools used for evaluation of Brazilian children's quality of life. Rev. Paul. Pediatr. [Internet]. 2014 [acesso em 03 set 2020]; 32(2). Disponível em: https://doi.org/10.1590/0103-0582201432214313.

5. Transgender Europe (TGEU). TMM annual report 2016. TVT publication series [Internet]. 2016 [acesso em 02 set 2020]; 14. Disponível em: https://transrespect.org/wp-content/uploads/2016/11/TvT-PSVol14-2016.pdf.

6. Vinuto J. A amostragem em bola de neve na pesquisa qualitativa: um debate em aberto. Temáticas [Internet]. 2014 [acesso em 15 ago 2020]; 22(44). Disponível em: https://doi.org/10.20396/tematicas. v22i44.10977.

7. Creswell JW. Investigação qualitativa e projeto de pesquisa: escolhendo entre cinco abordagens. 3. ed. Porto Alegre: Penso; 2014.

8. Fontanella BJB, Luchesi BM, Saidel MGB, Ricas J, Turato ER, Melo DG. Amostragem em pesquisas qualitativas: proposta de procedimentos para constatar saturação teórica. Cad. Saúde Pública [Internet]. 2011 [acesso em 15 ago 2020]; 27(2). Disponível em: https://doi.org/10.1590/S0102$\underline{311 \times 2011000200020 .}$.

9. Bardin L. Análise de conteúdo. São Paulo: Edições 70; 2011.

10. Camargo BV, Justo AM. IRAMUTEQ: um software gratuito para análise de dados textuais. Temas psicol [Internet]. 2013 [acesso em 18 ago 2020]; 21(2). Disponível em: https://doi.org/10.9788/TP2013.216.

11. Koizumi MS. Fundamentos metodológicos da pesquisa em enfermagem. Rev. esc. enferm. USP [Internet]. 1992 [acesso em 20 ago 2020]; 26. Disponível em: https://doi.org/10.1590/008062341992026esp00033.

12. Ministério da Saúde (BR). Conselho Nacional de Saúde. Diretrizes e normas regulamentadoras de pesquisa envolvendo seres humanos. Resolução n. 466, de 12 de dezembro de 2012. Brasília; 2012.

13. Ministério das Mulheres, da Igualdade Racial e dos Direitos Humanos (BR). Decreto n. 8727, de 28 de abril de 2016: dispõe sobre o uso do nome social e o reconhecimento da identidade de gênero de pessoas travestis e transexuais no âmbito da administração pública federal direta, autárquica e fundacional. Diário Oficial da União, [Internet]. 29 abr 2016 [acesso em 08 set 2020]. Disponível em: http://www.planalto.gov.br/ccivil 03/ ato2015-2018/2016/decreto/d8727.htm.

14. Brasil. Constituição da República Federativa do Brasil. Brasília: Senado; 1988.

15. Ministério da Saúde (BR). Secretaria de Gestão Estratégica e Participativa. Departamento de Apoio à Gestão Participativa. Política Nacional de Saúde Integral de Lésbicas, Gays, Bissexuais, Travestis e Transexuais. [Internet]. Brasília: Ministério da Saúde; 2013 [acesso em 02 set 2020]. Disponível em: http:// bvsms.saude.gov.br/bvs/publicacoes/politica nacional saude lesbicas gays.pdf.

16. Silva LKM da, Silva ALMA da, Coelho AA, Martiniano CS. Uso do nome social no Sistema Único de Saúde: elementos para o debate sobre a assistência prestada a travestis e transexuais. Physis [Internet]. 2017 [acesso em 17 mar 2021]; 27(03). Disponível em: https://doi.org/10.1590/S0103- 
17. Figueiredo R, Schwach K, Wolfe BM, McBritton M, Marquezine IM. Mudança de nome social de pessoas transgêneras: identidade de gênero para além da biologia. Bagoas - Estudos gays: gêneros e sexualidades [Internet]. 2017 [acesso em 22 ago 2020]; 11(17): 318-39. Disponível em: https://periodicos. ufrn.br/bagoas/article/view/11349.

18. Castel R. Da indigência à exclusão, a desfiliação: precariedade do trabalho e vulnerabilidade relacional. In: Lancetti A, organizador. Saúde loucura 4: grupos e coletivos. São Paulo: HUCITEC; 1994. p. 21-48.

19. Associação Nacional de Travestis e Transexuais (ANTRA). Mapa dos assassinatos de travestis e transexuais no Brasil em 2017. [Internet]. Brasília: ANTRA, 2018 [acesso em 07 set 2020]. Disponível em: https://antrabrasil.files.wordpress.com/2018/02/relatc3b3rio-mapa-dos-assassinatos-2017-antra.pdf.

20. Licciardi N, Waitmann G, Oliveira, MHM. A discriminação de mulheres travestis e transexuais no mercado de trabalho. Revista Científica Hermes [Internet]. 2015 [acesso em 17 mar 2021]; 14. Disponível em: https://www.redalyc.org/pdf/4776/477647161011.pdf.

21. Rondas L de O, Machado LR de S. Inserção profissional de travestis no mundo do trabalho: das estratégias pessoais às políticas de inclusão. Pesquisas e Práticas Psicossociais. [Internet]. 2015 [acesso em 22 ago 2020]; 10(1). Disponível em: https://ufsj.edu.br/portal2-repositorio/File/revistalapip/15 Rondas.pdf.

22. Segre M, Ferraz FC. O conceito de saúde. Rev. Saúde Pública [Internet]. 1997 [acesso em 30 ago 2020]; 31(5). Disponível em: http://dx.doi.org/10.1590/S0034-89101997000600016.

23. Czeresnia D. O conceito de saúde e a diferença entre prevenção e promoção. In: Czeresnia $D$, Freitas $\mathrm{CM}$, organizadores. Promoção da Saúde: conceitos, reflexões e tendências. Rio de Janeiro: Fiocruz; 2003. p. 39-53.

24.Garbois JA, Sodré F, Dalbello-Araújo M. Da noção de determinação social à de determinantes sociais da saúde. Saúde debate [Internet]. 2017 [acesso em 26 ago 2020]; 41(112). Disponível em: http://dx.doi. org/10.1590/0103-1104201711206.

25. Dias JAH, Bernardineli MC. O transexual e o direito de acesso ao mercado de trabalho: do preconceito à ausência de oportunidades. Revista de Gênero, Sexualidade e Direito [Internet]. 2016 [acesso em 04 set 2020]; 2(2). Disponível em: http://dx.doi.org/10.26668/2525-9849/Index Law Journals/2016.v2i2.1376.

26. Organização das Nações Unidas (ONU). Declaração Universal dos Direitos Humanos. [Internet]. Paris: ONU; 1948. [acesso em 02 ago 2020]. Disponível em: https://www.oas.org/dil/port/1948\%20 Declara\%C3\%A7\%C3\%A30\%20Universal\%20dos\%20Direitos\%20Humanos.pdf. 


\section{TRAVESTIS PROFISSIONAIS DO SEXO E QUALIDADE DE VIDA: VISIBILIZANDO OUTRAS CONCEPÇÕES}

\section{RESUMO:}

Objetivo: compreender a percepção da qualidade de vida de travestis profissionais do sexo. Método: estudo qualitativo e exploratório. Partiu-se de um espaço social na cidade de Recife, Pernambuco, Brasil. As participantes foram localizadas a partir da técnica snowball. Aplicou-se questionário semiestruturado com perguntas guias, com a participação de sete participantes, mediante a saturação teórica. Os dados foram gravados e analisados a partir da análise temática de conteúdo e análise de similitude. Para validação e confiabilidade, adotou-se a triangulação metodológica e de pesquisadores. Resultados: obtiveram-se três classes: "Respeito ao nome social e reconhecimento da identidade trans"; "A importância da inserção e empregabilidade formal" e "Bem-estar social, educação e moradia". Resultou-se na árvore de similitude com as palavras com mais significância. Conclusão: foi possível identificar outras narrativas sobre a qualidade de vida das travestis profissionais do sexo, que fissuram o senso comum que atrela às travestis toda e qualquer concepção marginalizada e ininteligível.

DESCRITORES: Qualidade de Vida; Pessoas Transgênero; Profissionais do Sexo; Minorias Sexuais e de Gênero; Enfermagem.

\section{TRAVESTIS QUE TRABAJAN COMO PROFESIONALES DEL SEXO Y CALIDAD DE VIDA: VISIBILIZANDO OTRAS CONCEPCIONES}

\section{RESUMEN:}

Objetivo: comprender la percepción de la calidad de vida de travestis que trabajan como profesionales del sexo. Método: estudio cualitativo e exploratorio. El punto de partida fue un espacio social de la ciudad de Recife, Pernambuco, Brasil. Las participantes fueron localizadas a partir de la técnica snowball. Se aplicó un cuestionario semiestructurado con preguntas orientadoras, con la participación de siete sujetos, mediante saturación teórica. Los datos se grabaron y analizaron a partir del análisis temático de contenido y del análisis de similitud. Para la validación y confiabilidad se adoptó triangulación metodológica y de investigadores. Resultados: se obtuvieron tres clases: "Respeto por el nombre social y reconocimiento de la identidad trans"; "La importancia de la inserción y posibilidad de empleo formal" y "Bienestar social, educación y vivienda". El resultado fue un árbol de similitud con las palabras de mayor significancia. Conclusión: fue posible identificar otras narrativas sobre la calidad de vida de las travestis que trabajan como profesionales del sexo, que rompen con el sentido común que vincula todas y cada una de las concepciones marginalizadas e ininteligibles a las travestis.

DESCRIPTORES: Calidad de Vida; Personas Transgénero; Profesionales del Sexo; Minorías Sexuales y de Género; Enfermería.

Recebido em: 01/10/2020

Aprovado em: 14/04/2021

Editora associada: Luciana Alcântara Nogueira

Autor Correspondente:

Alef Diogo da Silva Santana

Universidade de São Paulo - Ribeirão Preto, SP, Brasil

E-mail: alefeerp@usp.br

Contribuição dos autores:

Contribuições substanciais para a concepção ou desenho do estudo; ou a aquisição, análise ou interpretação de dados do estudo - Barbosa ALS, Santana AD da S, Araújo EC de, Moura JWS da, Lima MS de; Elaboração e revisão crítica do conteúdo intelectual do estudo - Barbosa ALS, Santana AD da S, Araújo EC de, Moura JWS da, Lima MS de. Todos os autores aprovaram a versão final do texto.

Copyright (? 2021 Este é um artigo em acesso aberto distribuído nos termos da Licença Creative Commons Atribuição, que permite o uso irrestrito, a distribuição e reprodução em qualquer meio desde que o artigo original seja devidamente citado. 